\title{
Hylan A: A Novel Transporter for Latanoprost in the Treatment of Ocular Hypertension
}

\author{
Wolfgang GK Müller-Lierheim* \\ CORONIS GmbH, Kaflerstr, 15, 81241 München, Germany \\ *Corresponding author: Wolfgang GK Müller-Lierheim, CORONIS GmbH, Kaflerstr. 15, 81241 München, Germany
}

\section{ARTICLE INFO}

Received: 幽 July 02, 2021

Published: 幽 July 13, 2021

Citation: Wolfgang GK Müller-Lierheim. Hylan A: A Novel Transporter for Latanoprost in the Treatment of Ocular Hypertension. Biomed J Sci \& Tech Res 37(1)2021. BJSTR. MS.ID.005957.

Keywords: Latanoprost; Prostaglandin Analogues; Hylan A; Hyaluronan; Sodium Hyaluronate; Drug Vehicle; Drug Transporter; Eye Drops; Glaucoma; Ocular Hypertension

\begin{abstract}
Eye drops containing prostaglandin analogues such as latanoprost are the first line therapy in the long-term prevention and treatment of primary open angle glaucoma (POAG). The formulation of stable latanoprost eye drops supporting the latanoprost transport across the epithelial barrier has so far resulted in vehicles which in a significant percentage of patients are causing progressive damage to the ocular surface. A vehicle composed exclusively of substances which are naturally present in the ocular surface, and which can transport latanoprost into the eye without compromising the ocular surface has been developed. Shelf-life tests and a clinical screening test on a person with ocular hypertension have been performed. The vehicle is capable to provide a solution of $20 \mu \mathrm{g} / \mathrm{ml}$ latanoprost reasonably stable during storage at $25^{\circ} \mathrm{C} / 60 \%$ relative humidity $(\mathrm{RH})$. A prototype latanoprost eye drop solution with $0.15 \%$ very high molecular weight hyaluronan (hylan A) containing $19 \mu \mathrm{g} / \mathrm{ml}$ latanoprost caused an intraocular pressure (IOP) reduction of $5.87 \mathrm{~mm} \mathrm{Hg}$ in the eyes of the test person, as compared to $3.24 \mathrm{~mm} \mathrm{Hg}$ reduction achieved by the application of commercial latanoprost eye drops containing $50 \mu \mathrm{g} / \mathrm{ml}$ latanoprost. This is the first evidence that hylan A does not only act as a mucoadhesive viscosity enhancer in drug vehicles but can act as a transporter for active pharmaceutical ingredients (API) into the eye.
\end{abstract}

\section{Introduction}

Glaucoma is the second leading cause of blindness after cataracts and is usually irreversible [1]. It is expected that by 2020 approximately 76 million people suffered from glaucoma and that this number will reach 112 million by 2040 [1]. Ocular hypertension (OHT) is a leading risk factor for the development of POAG and, lowering the intraocular pressure (IOP) is the only therapeutic option to prevent or delay the development of POAG [2]. Prostaglandin analogues such as latanoprost are the most effective active pharmaceutical ingredients (API) for lowering the IOP [3]. Current eye drops for the treatment of OHT and POAG are known for their high incidence of immediate as well as longterm undesirable side effects [4]. They are associated with a high incidence of progressive glaucoma therapy-related ocular surface disease (OSD) [5]. Undesirable side effects may either be intrinsic, i.e. caused by the API or caused by excipients contained in the vehicle [6]. The vehicle is intended to dissolve or suspend the API, stabilize the solution during shelf-life of the eye drops and during patient use, prolong the contact time between the API and the ocular surface, support the penetration of the API into the ocular surface, and enhance the biocompatibility of the eye drops $[7,8]$. Latanoprost in aqueous solution is known to require stabilization [9-13]. Today most commercial latanoprost eye drops contain the quaternary ammonium cationic detergent benzalkonium chloride (BAC) as a preservative and penetration enhancer. The devastating long-term effects of BAC on the ocular surface are proverbial [14]. Recently preservative-free IOP lowering eye drops have become available, avoiding the long-term effects of BAC $[5,15,16]$. Although less oculotoxic, these eye drops also contain penetration enhancers such as EDTA, compromising the epithelial barrier, with the potential of causing long-term damage to the ocular surface [17-19]. The use of hyaluronic acid (HA) as mucoadhesive thickening agent in drug vehicles has been suggested in the literature [20-28]. HA has 
been shown to counteract the irritating effect of substances to the ocular epithelium [29-33]. Recent studies have shown that hylan A in eye drops does not only provide hydration and lubrication of the ocular surface, but seems to enter the epithelium, where it acts antiinflammatory and provides neurotrophic support to compromised epithelial nerves [34-36]. The current study intended to investigate, if the polyanion hylan $\mathrm{A}$ is able to act as an influx transporter enhancing the solubility and stability of latanoprost and facilitating its translocation across the ocular epithelial barrier [37].

\section{Materials and Methods}

\section{Materials}

Sterile bulk solution for the production of Comfort Shield ${ }^{\circledR}$ MDS eye drops (i.com medical GmbH, Munich, Germany) was used as vehicle for the preparation of prototype latanoprost bulk solution (PLBS). The vehicle contained $0.15 \% \mathrm{w} / \mathrm{v}$ hylan A (HA with $2.9 \mathrm{~m}^{3} / \mathrm{kg}$ intrinsic viscosity) dissolved in phosphate buffered saline solution (8.035 g/l NaCl; $1.2 \mathrm{mmol} / \mathrm{l} \mathrm{Na}_{2} \mathrm{HPO}_{4} / \mathrm{NaH}_{2} \mathrm{PO}_{4}$; $\mathrm{pH}$ 7.4). Latanoprost was obtained from Yonsung Fine Chemicals Co. Ltd., Gyeonggi-do, Republic of Korea. PLBS was prepared by medipharm Laboratorium $\mathrm{GmbH}$, Falkensee, Germany by dissolving $20 \pm 1 \mu \mathrm{g} / \mathrm{ml}$ latanoprost in the vehicle. Sterile $10 \mathrm{ml}$ bottles with Ophthalmic Squeeze Dispenser (OSD) were obtained from Aptar Radolfzell GmbH, Radolfzell, Germany. Medi-pharm Laboratorium GmbH prepared two batches of prototype latanoprost test samples (PLTS-A) for stability screening, by aseptically filling $9 \mathrm{ml}$ of PLBS into Aptar bottles and closing them with the OSD dispenser.

Sterile Novelia ${ }^{\circledR} 11 \mathrm{ml}$ soft bottles and PureFlow® 1500 droppers with valve diameter 1.6 were obtained from Nemera, La Verpillière, France. Pharmpur GmbH, Königsbrunn, Germany prepared prototype latanoprost test samples (PLTS-N) for the IOP self-test by aseptically filling $10 \mathrm{ml}$ of PLBS into sterile Novelia bottles and closing them with the droppers. These test samples had to be kept vertical to minimize the contact between the solution and the dropper, as latanoprost has a tendency to adsorb to silicone parts contained in the dropper. The latanoprost concentration in the PLTS-N bottle used for the self-test was $19 \mu \mathrm{g} / \mathrm{ml}$. Xalatan ${ }^{\circledR}$ eye drops (PFIZER OFG Germany GmbH, Berlin, Germany) containing 50 $\mu \mathrm{g} / \mathrm{ml}$ latanoprost, $0.2 \mathrm{mg} / \mathrm{ml} \mathrm{BAC}$ and $6.3 \mathrm{mg} / \mathrm{ml}$ phosphates were used as comparative samples in the IOP self-test. Comfort Shield ${ }^{\circledR}$ MDS $0.15 \%$ hylan A eye drops (i.com medical GmbH, Munich, Germany), composed of the vehicle of the prototype latanoprost test samples, were used as control and during the wash-out period in the IOP self-test.

\section{Test Subject}

The test subject (TS) is a 71-year-old, male, with healthy ocular surface, without history of ocular trauma or ocular surgery or use of preserved eye drops, with untreated ocular hypertension not associated with glaucoma.

\section{Methods}

In a pre-test $25 \mu \mathrm{g} / \mathrm{ml}$ and $50 \mu \mathrm{g} / \mathrm{ml}$ latanoprost were added to the vehicle and the solution stirred for 18 hours at $40{ }^{\circ} \mathrm{C}$. The latanoprost content was determined by HPLC using a Hypersil BDS

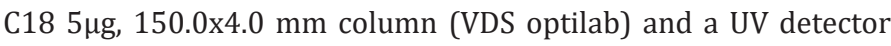
(200 nm). Independent from the starting amount, $20.8 \mu \mathrm{g} / \mathrm{ml}$ latanoprost were found to be dissolved in the vehicle as compared to a solubility of $12.9 \mu \mathrm{g} / \mathrm{ml}$ latanoprost in water [38]. Samples from two batches of PLTS-A were stored for six months at ambient room temperature $\left(15-25^{\circ} \mathrm{C}\right)$, at $2-8{ }^{\circ} \mathrm{C}$, at $25^{\circ} \mathrm{C} / 60 \% \mathrm{RH}$, and at $40{ }^{\circ} \mathrm{C} /$ $75 \%$ RH. Initially, after 4 weeks, after 3 months, and after 6 months samples were visually inspected for appearance (clarity) and absence of particles, and tested for $\mathrm{pH}$ value, latanoprost content, and loss of weight. Throughout the self-test IOP was measured using a hand-held iCare HOME Model TA022 rebound tonometer intended for self-use (Icare Finland Oy, Vantaa, Finland) [39]. Triple measurements were taken, and the average values noted.

IOP is known to fluctuate widely during the 24-hour (circadian) period, and, moreover, that the time of the peak of IOP varies from patient to patient $[40,41]$. Less is known about the day to day (interdian) variability of the IOP. Therefore, the TS measured the IOP of both eyes on seven consecutive days at 08:00 (8 a.m.), 11:00 (11 a.m.), 15:00 (3 p.m.), 19:00 (7 p.m.) and 22:00 (10 p.m.). The individual time of peak IOP of the TS (11:00) was chosen for the IOP monitoring throughout the screening test. Eight weeks before the self-test the TS applied one drop of Comfort Shield MDS eye drops (= vehicle) in each eye in the morning and evening. The self-test lasted over a period of five weeks, and the IOP of both eyes was measured daily at 11:00. In week 1,3 , and 4 the vehicle was applied in the morning and evening. During weeks 2 and 5 the vehicle was only applied in the morning (between 7:00 and 8:00) and one drop of latanoprost eye drops was instilled in each eye between 19:00 and 20:00 in the evening. During week 2 Xalatan $®$ eye drops (50 $\mu \mathrm{g} / \mathrm{ml}$ latanoprost) were applied, whereas, in week 5 PLTS-N eye drops $(19 \mu \mathrm{g} / \mathrm{ml}$ latanoprost $)$ were instilled.

\section{Results}

\section{Stability Screening}

The results of stability screening for two batches of prototype latanoprost test samples (PLTS-A) are summarized in Tables 1 and 2.

\section{IOP Self-Test}

In order to study the individual circadian rhythm and interdian variability the TS performed IOP measurements on seven consecutive days. The IOP of the TS reached a peak in the late morning followed by a continuous decrease until the evening (see Table 3). Based on the results of this test it was decided to perform IOP measurements at 11:00 for the comparison of the effectiveness 
of latanoprost eye drops in the eyes of the TS. There were also significant differences from day to day, therefore, IOP measurements with and without latanoprost eye drops were performed on seven consecutive days (Table 4). Upon the application of commercial eye drops containing $50 \mu \mathrm{g} / \mathrm{ml}$ latanoprost the intraocular pressure decreased by $3.24 \mathrm{~mm} \mathrm{Hg}$ from an average baseline value of 27.62 $\mathrm{mm} \mathrm{Hg}$ to an average value of $24.38 \mathrm{~mm} \mathrm{Hg}$, whereas the prototype latanoprost test sample PLTS-N containing only $19 \mu \mathrm{g} / \mathrm{ml}$ resulted in an IOP decrease of $5.87 \mathrm{~mm} \mathrm{Hg}$ from an average baseline value of $27.30 \mathrm{~mm} \mathrm{Hg}$ to an average value of $21.43 \mathrm{~mm} \mathrm{Hg}$.

Table 1: Results of stability testing on PLTS-A, batch E030219.

\begin{tabular}{|c|c|c|c|c|c|}
\hline Storage Condition & Test Parameter & Initially & 4 Weeks & 3 Months & 6 Months \\
\hline \multirow{5}{*}{$15-25^{\circ} \mathrm{C}$} & appearance & clear & clear & clear & clear \\
\hline & particles & not visible & not visible & not visible & not visible \\
\hline & $\mathrm{pH}$ value & 7,06 & 7,02 & 7,01 & 6,25 \\
\hline & latanoprost content $(\mu \mathrm{g} / \mathrm{ml})$ & 20,66 & 20,74 & 20,20 & 20,62 \\
\hline & weight loss & 0,00 & 0,19 & 0,71 & 2,55 \\
\hline \multirow{5}{*}{$2-8^{\circ} \mathrm{C}$} & appearance & clear & clear & clear & clear \\
\hline & particles & not visible & not visible & not visible & not visible \\
\hline & $\mathrm{pH}$ value & 7,06 & 6,99 & 7,03 & 6,38 \\
\hline & latanoprost content $(\mu \mathrm{g} / \mathrm{ml})$ & 20,66 & 20,56 & 20,68 & 18,68 \\
\hline & weight loss & 0,00 & 0,05 & 0,07 & 0,96 \\
\hline \multirow{5}{*}{$25^{\circ} \mathrm{C} / 60 \% \mathrm{RH}$} & appearance & clear & clear & clear & clear \\
\hline & particles & not visible & not visible & not visible & not visible \\
\hline & $\mathrm{pH}$ value & 7,06 & 7,03 & 6,95 & 6,27 \\
\hline & latanoprost content $(\mu \mathrm{g} / \mathrm{ml})$ & 20,66 & 20,56 & 20,35 & 20,20 \\
\hline & weight loss & 0,00 & 0,37 & 1,78 & 4,80 \\
\hline \multirow{5}{*}{$40^{\circ} \mathrm{C} / 75 \% \mathrm{RH}$} & appearance & clear & clear & clear & clear \\
\hline & particles & not visible & not visible & not visible & not visible \\
\hline & $\mathrm{pH}$ value & 7,06 & 6,96 & 6,66 & 5,81 \\
\hline & latanoprost content $(\mu \mathrm{g} / \mathrm{ml})$ & 20,66 & 18,96 & 18,43 & 11,64 \\
\hline & weight loss & 0,00 & 0,81 & 2,01 & 5,05 \\
\hline
\end{tabular}

Table 2: Results of stability testing on PLTS-A, batch E040219.

\begin{tabular}{|c|c|c|c|c|c|}
\hline Storage Condition & Test Parameter & Initially & 4 Weeks & 3 Months & 6 Months \\
\hline \multirow{5}{*}{$15-25^{\circ} \mathrm{C}$} & appearance & clear & clear & clear & clear \\
\hline & particles & not visible & not visible & not visible & not visible \\
\hline & $\mathrm{pH}$ value & 7,06 & 7,04 & 7,03 & 6,22 \\
\hline & latanoprost content $(\mu \mathrm{g} / \mathrm{ml})$ & 20,88 & 20,30 & 20,15 & 20,11 \\
\hline & weight loss & 0,00 & 0,26 & 0,80 & n.d.* \\
\hline \multirow{5}{*}{$2-8^{\circ} \mathrm{C}$} & appearance & clear & clear & clear & clear \\
\hline & particles & not visible & not visible & not visible & not visible \\
\hline & $\mathrm{pH}$ value & 7,06 & 7,10 & 7,07 & 6,36 \\
\hline & latanoprost content $(\mu \mathrm{g} / \mathrm{ml})$ & 20,88 & 20,64 & 20,14 & 19,59 \\
\hline & weight loss & 0,00 & 0,04 & 0,07 & n.d. \\
\hline \multirow{5}{*}{$25^{\circ} \mathrm{C} / 60 \% \mathrm{RH}$} & appearance & clear & clear & clear & clear \\
\hline & particles & not visible & not visible & not visible & not visible \\
\hline & $\mathrm{pH}$ value & 7,06 & 7,04 & 6,97 & 6,25 \\
\hline & latanoprost content $(\mu \mathrm{g} / \mathrm{ml})$ & 20,88 & 19,52 & 19,53 & 19,33 \\
\hline & weight loss & 0,00 & 0,31 & 0,84 & n.d. \\
\hline
\end{tabular}




\begin{tabular}{|c|c|c|c|c|c|}
\hline \multirow{5}{*}{$40{ }^{\circ} \mathrm{C} / 75 \% \mathrm{RH}$} & appearance & clear & clear & clear & clear \\
\hline & particles & not visible & not visible & not visible & not visible \\
\hline & $\mathrm{pH}$ value & 7,06 & 6,87 & 6,73 & 5,88 \\
\hline & latanoprost content $(\mu \mathrm{g} / \mathrm{ml})$ & 20,88 & 17,50 & 13,58 & 10,50 \\
\hline & weight loss & 0,00 & 0,61 & 1,61 & n.d. \\
\hline
\end{tabular}

Note: ${ }^{*}$ n.d. $=$ not determined

Table 3: Circadian and interdian variation of IOP in the right (OD) and left eye (OS) of the TS.

\begin{tabular}{|c|c|c|c|c|c|c|c|c|c|c|}
\hline \multirow{2}{*}{ Time } & \multicolumn{5}{|c|}{ IOP OD in mm $\mathrm{Hg}$} & \multicolumn{5}{|c|}{ IOP OS in $\mathrm{mm} \mathrm{Hg}$} \\
\hline & 8:00 & 11:00 & $15: 00$ & 19:00 & 22:00 & 8:00 & 11:00 & $15: 00$ & 19:00 & 22:00 \\
\hline day 1 & 27,0 & 29,3 & 26,7 & 24,0 & 22,3 & 25,3 & 28,3 & 25,3 & 23,0 & 22,7 \\
\hline day 2 & 24,7 & 29,3 & 30,0 & 24,7 & 24,3 & 24,7 & 26,3 & 28,7 & 25,7 & 23,0 \\
\hline day 3 & 28,7 & 31,7 & 27,3 & 24,3 & 25,3 & 28,3 & 30,0 & 26,0 & 24,3 & 23,7 \\
\hline day 4 & 25,7 & 29,3 & 25,7 & 24,3 & 24,7 & 25,0 & 27,3 & 26,0 & 23,3 & 23,3 \\
\hline day 5 & 29,7 & 26,3 & 27,7 & 27,3 & 25,7 & 29,3 & 25,7 & 27,7 & 26,0 & 24,7 \\
\hline day 6 & 27,3 & 31,0 & 28,7 & 29,0 & 24,0 & 26,3 & 30,7 & 29,7 & 27,0 & 22,0 \\
\hline day 7 & 25,7 & 29,7 & 28,3 & 25,3 & 26,3 & 25,0 & 30,3 & 29,3 & 25,3 & 26,7 \\
\hline mean IOP & 27,0 & 29,5 & 27,8 & 25,6 & 24,7 & 26,3 & 28,4 & 27,5 & 25,0 & 23,7 \\
\hline standard deviation & 1,8 & 1,7 & 1,4 & 1,9 & 1,3 & 1,8 & 2,0 & 1,8 & 1,5 & 1,5 \\
\hline
\end{tabular}

Table 4: IOP values before (week 1) and during the application of commercial $50 \mu \mathrm{g} / \mathrm{ml}$ latanoprost eye drops (week 2), and IOP values before (week 4) and during the application of PLTS-N $19 \mu \mathrm{g} / \mathrm{ml}$ lathanoprost eye drops (week 5).

\begin{tabular}{|c|c|c|c|c|c|c|c|c|}
\hline \multirow[t]{2}{*}{ IOP in $\mathrm{mm} \mathrm{Hg}$} & \multicolumn{2}{|c|}{ week 1 vehicle } & \multicolumn{2}{|c|}{$\begin{array}{c}\text { week } 2 \text { lathanoprost } 50 \\
\mu \mathrm{g} / \mathrm{ml}\end{array}$} & \multicolumn{2}{|c|}{ week 4 vehicle } & \multicolumn{2}{|c|}{ week 5 PLTS-N $19 \mu \mathrm{g} / \mathrm{ml}$} \\
\hline & OD & OS & OD & OS & OD & os & OD & os \\
\hline day 1 & 24,67 & 26,33 & 23,33 & 25,00 & 26,00 & 27,00 & 22,67 & 23,00 \\
\hline day 2 & 26,33 & 27,67 & 23,00 & 26,00 & 28,67 & 28,00 & 20,67 & 23,00 \\
\hline day 3 & 28,33 & 30,33 & 22,67 & 24,00 & 27,33 & 28,33 & 24,67 & 24,67 \\
\hline day 4 & 27,00 & 28,67 & 23,33 & 24,00 & 22,33 & 24,33 & 19,67 & 20,33 \\
\hline day 5 & 25,67 & 27,67 & 23,67 & 25,67 & 28,00 & 28,67 & 17,00 & 19,33 \\
\hline day 6 & 29,33 & 29,00 & 23,00 & 25,00 & 27,00 & 28,33 & 22,00 & 20,33 \\
\hline day 7 & 27,67 & 28,00 & 26,33 & 26,33 & 29,00 & 29,33 & 20,33 & 22,33 \\
\hline mean IOP & 27,00 & 28,24 & 23,62 & 25,14 & 26,90 & 27,71 & 21,00 & 21,86 \\
\hline standard deviation & 1,60 & 1,26 & 1,24 & 0,92 & 2,26 & 1,65 & 2,44 & 1,91 \\
\hline
\end{tabular}

\section{Discussion}

Eye drops for the topical treatment of diseases are composed of an active pharmaceutical ingredient (API) with pharmacological, metabolic or immunological activity, dissolved or suspended in a vehicle. Potential functions of the vehicle include dissolving or suspending the API, stabilizing the solution during shelf-life of the eye drops and during patient use, prolonging the contact time between the API and the ocular surface, supporting the penetration of the API into the ocular surface, and enhancing the biocompatibility of the eye drops [7,8]. Most eye drop formulations are requiring additives, in particular surfactants to dissolve lipophilic APIs like latanoprost. Mucoadhesive polymers like HA are prolonging the contact time by increasing the viscosity, and can, moreover, adhere to the glycocalyx of the apical epithelial cells, thus promoting the contact between the API and the ocular surface. Penetration enhancers such as BAC or EDTA weaken the transcellular or paracellular epithelial barrier function, thus enhancing the diffusion of the API into the ocular surface.

For reasons of acute and long-term biocompatibility it would be desirable to use vehicles which exclusively contain substances naturally occurring in the eye which, moreover, support ocular surface homeostasis and minimize unintended side effects of the API. Previous clinical investigations have proven this potential for a preservative-free solution comprised of $0.15 \% \mathrm{v} / \mathrm{w}$ hylan $\mathrm{A}$ dissolved in isotonic phosphate buffered saline solution with $\mathrm{pH} 7.4$ [34-36]. It could be shown that this solution used as a vehicle result 
in a stable solution of $20 \mu \mathrm{g} / \mathrm{ml}$ latanoprost. It is hypothesized that the extra amount of $8 \mu \mathrm{g} / \mathrm{ml}$ latanoprost dissolved in the vehicle in excess of the latanoprost solubility in water is attributable to the association of latanoprost with the polyanion hylan A. Surprisingly the novel vehicle resulted in one test person with ocular hypertension in a superior IOP lowering effect as compared to commercial latanoprost eye drops with significantly higher latanoprost concentration. This seems strong evidence in favor of the assumption that hylan A acts as an influx transporter for latanoprost into the eye. This observation will need to be verified in a larger number of test subjects.

Beyond that, it will be of interest to investigate, if hylan A can also be used as an influx transporter for other APIs in the treatment of ocular diseases, eventually including retinal diseases, and if it can eventually contribute to a lower API concentration in eye drops, thus ameliorating intrinsic unintended side effects of the API, and, moreover, lowering manufacturing costs. The mode of action of hylan A as a transporter is so far unclear. Beyond stabilizing the epithelial barrier function, acting as an anti-inflammatory agent, and promoting intimate prolonged contact of latanoprost to the ocular surface, it is hypothesized that hylan A as a transporter with latanoprost associated, may bind to mucin MUC16 in the glycocalyx of the apical epithelial cells; may bind to adhesion molecule CD44 and to the receptor for hyaluronic acid-mediated motility (RHAMM) on the apical surface of the corneal and conjunctival epithelium; increases local tissue hydration, enabling temporal cell detachment that may create passages allowing for cell migration and transport of bioactive agents along the paracellular pathway; and binds to the HA receptor for endocytosis (HARE) on the apical surface of the corneal and conjunctival epithelium, causing HAREmediated endocytosis of the bioactive agent into the cytoplasm of the epithelial cells. The latter would be a novel option to transport bioactive agents with hylan A molecules as a transporter through the cell membrane of epithelial cells without damaging the cell membrane. In combination with the ability of hylan A to ameliorate the negative effects of corneotoxic substances, and lower concentration of API in eye drops, it is anticipated that patients will benefit from this novel vehicle and transporter in ocular diseases requiring long-term treatment..

\section{Patents}

Based on the results of this study i.com medical GmbH, Munich, Germany filed an international patent application.

\section{Funding}

This research received no external funding.

\section{Institutional Review Board Statement}

This study was conducted under the sole responsibility of the author, only involving the author as test subject. The self- test was performed to ensure that subsequently intended animal experiments are likely to generate valuable clinical data.

\section{Conflicts of Interest}

The author is CEO and shareholder of i.com medical GmbH, Munich, Germany.

\section{References}

1. Karen Allison, Deepkumar Patel, Omobolanle Alabi (2020) Epidemiology of Glaucoma: The Past, Present, and Predictions for the Future. Cureus 12(11): p. e11686-e11686.

2. Michael A Kass, Dale K Heuer, Eve J Higginbotham, Richard K Parrish, Cheryl L Khanna, et al. (2021) Assessment of Cumulative Incidence and Severity of Primary Open-Angle Glaucoma Among Participants in the Ocular Hypertension Treatment Study After 20 Years of Follow-up. JAMA Ophthalmol.

3. Tianjing Li, Kristina Lindsley, Benjamin Rouse, Hwanhee Hong, Qiyuan Shi, et al. (2016) Comparative Effectiveness of First-Line Medications for Primary Open-Angle Glaucoma: A Systematic Review and Network Meta-analysis. Ophthalmology 123(1): 129-140.

4. Cracknell KP, I Grierson (2009) Prostaglandin analogues in the anterior eye: their pressure lowering action and side effects. Exp Eye Res 88(4): 786-791.

5. Anastasios G Konstas, Antoine Labbé, Andreas Katsanos, Frances MeierGibbons, Murat Irkec, et al. (2021) The treatment of glaucoma using topical preservative-free agents: an evaluation of safety and tolerability. Expert Opin Drug Saf 20(4): 453-466.

6. Yiran Yang, Caihong Huang, Xiang Lin, Yang Wu, Weijie Ouyang, et al. (2018) $0.005 \%$ Preservative-Free Latanoprost Induces Dry EyeLike Ocular Surface Damage via Promotion of Inflammation in Mice. Investigative Ophthalmology \& Visual Science 59(8): 3375-3384.

7. Morrison PW, VV Khutoryanskiy (2014) Advances in ophthalmic drug delivery. Ther Deliv 5(12): 1297-1315.

8. Roman V Moiseev, Peter W. J. Morrison, Fraser Steele, Vitaliy V Khutoryanskiy (2019) Penetration Enhancers in Ocular Drug Delivery. Pharmaceutics 11(7).

9. Sakai Y, S Yasueda, A Ohtori (2005) Stability of latanoprost in an ophthalmic lipid emulsion using polyvinyl alcohol. Int J Pharm305(1-2): 176-179.

10. Ochiai A, K Danjo (2011) The stabilization mechanism of latanoprost. Int J Pharm 410(1-2): 23-30.

11. Ochiai A, M Ohkuma, K Danjo (2012) Investigation of surfactants suitable for stabilizing of latanoprost. Int J Pharm 436(1-2): 732-737.

12. Jayaganesh V Natarajan, Marcus Ang, Anastasia Darwitan, Sujay Chattopadhyay, Tina T Wong, et al. (2012) Nanomedicine for glaucoma: liposomes provide sustained release of latanoprost in the eye. Int J Nanomedicine 7: 123-131.

13. Xiangying Zhou, Xiaolin Li, Jiangmin Xu, Yanju Cheng, Feng Cao (2021) Latanoprost-loaded cyclodextrin microaggregate suspension eye drops for enhanced bioavailability and stability. Eur J Pharm Sci 160: 105758.

14. Christophe Baudouin, Antoine Labbé, Hong Liang, Aude Pauly, Françoise Brignole-Baudouin (2010) Preservatives in eyedrops: the good, the bad and the ugly. Prog Retin Eye Res 29(4): 312-334.

15. Gábor Holló, Andreas Katsanos, Kostas G Boboridis, Murat Irkec, Anastasios G P Konstas (2018) Preservative-Free Prostaglandin Analogs and Prostaglandin/Timolol Fixed Combinations in the Treatment of Glaucoma: Efficacy, Safety and Potential Advantages. Drugs 78(1): 3964. 
16. Joon Mo Kim, Sang Woo Park, Mincheol Seong, Seung Joo Ha, Ji Woong Lee, et al. (2021) Comparison of the Safety and Efficacy between Preserved and Preservative-Free Latanoprost and Preservative-Free Tafluprost. Pharmaceuticals (Basel) 14(6).

17. Bennett NH (2020) Material, Immunological, and Practical Perspectives on Eye Drop Formulation. Advanced Functional Materials 30(14): 1908476

18. Edoardo Villani, Matteo Sacchi, Fabrizio Magnani, Angelo Nicodemo, Susan E I Williams, et al. (2016) The Ocular Surface in Medically Controlled Glaucoma: An In Vivo Confocal Study. Invest Ophthalmol Vis Sci 57(3): 1003-1010.

19. Halder A, AJ Khopade (2020) Physiochemical Properties and Cytotoxicity of a Benzalkonium Chloride-Free, Micellar Emulsion Ophthalmic Formulation of Latanoprost. Clin Ophthalmol 14: 3057-3064.

20. Kaur IP, R Smitha (2002) Penetration enhancers and ocular bioadhesives: two new avenues for ophthalmic drug delivery. Drug Dev Ind Pharm 28(4): 353-369.

21. R Gurny, H Ibrahim, A AebiP Buri, CG Wilson, N Washington, et al. (1987) Design and evaluation of controlled release systems for the eye. J Controlled Release 6: 367-373.

22. Marco F Saettone, Patrizia Chetoni, Maria Tilde Torracca, Susi Burgalassi, Boris Giannaccini (1989) Evaluation of muco-adhesive properties and in vivo activity of ophthalmic vihicles based on hyaluronic acid. Int J Pharm 51: 203-212.

23. Saettone MF, Giannaccini B, Chetoni P, Torracca MT, Monti D (1991) Evaluation of high- and low-molecular-weight fractions of sodium hyaluronate and an ionic complex as adjuvants for ophthalmic vehicles containing pilocarpine. Int J Pharm 72: 131-139.

24. Brown MB, SA. Jones (2005) Hyaluronic acid: a unique topical vehicle for the localized delivery of drugs to the skin. J Eur Acad Dermatol Venereol 19(3): 308-318.

25. Yong-Hong Liao, Stuart A Jones, Ben Forbes, Gary P Martin, Marc B Brown (2005) Hyaluronan: pharmaceutical characterization and drug delivery. Drug Deliv 12(6): 327-342.

26. Khan R, B Mahendhiran, V Aroulmoji (2013) Chemistry of hyaluronic acid and its significance in drug delivery strategies: a review. Int J Pharm Sci \& Res 4(10): 3699-3710.

27. Park K, JR Robinson (1984) Bioadhesive polymers as platforms for oralcontrolled drug delivery: method to study bioadhesion. Int J Pharm 19(2): 107-127.

28. Natallia Dubashynskaya, Daria Poshina, Sergei Raik, Arto Urtti, Yury A Skorik (2019) Polysaccharides in Ocular Drug Delivery. Pharmaceutics 12(1): 22.

29. Y S Wysenbeek, N Loya, I Ben Sira, I Ophir, Y Ben Shaul (1988) The effect of sodium hyaluronate on the corneal epithelium. An ultrastructural study. Invest Ophthalmol Vis Sci 29(2): 194-199.

ISSN: 2574-1241

DOI: 10.26717/BJSTR.2021.37.005958

Wolfgang GK Müller-Lierheim. Biomed J Sci \& Tech Res

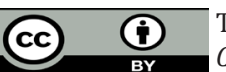

This work is licensed under Creative Commons Attribution 4.0 License

Submission Link: https://biomedres.us/submit-manuscript.php
30. Thierry Pauloin, Mélody Dutot, Hong Liang, Emilie Chavinier, JeanMichel Warnet, et al. (2009) Corneal protection with high-molecularweight hyaluronan against in vitro and in vivo sodium lauryl sulfateinduced toxic effects. Cornea 28(9): 1032-1041.

31. Xing Liu, Fen-Fen Yu, Yi-Min Zhong, Xin-Xing Guo, Zhen Mao (2015) Therapeutic Effects of Sodium Hyaluronate on Ocular Surface Damage Induced by Benzalkonium Chloride Preserved Anti-Glaucoma Medications. Chin Med J (Engl) 128(18): 2444-2449.

32. Thierry Pauloin, Mélody Dutot, Jean-Michel Warnet, Patrice Rat (2008) In vitro modulation of preservative toxicity: high molecular weight hyaluronan decreases apoptosis and oxidative stress induced by benzalkonium chloride. Eur J Pharm Sci 34(4-5): 263-273.

33. Fenfen Yu, Xing Liu, Yimin Zhong, Xinxing Guo, Mei Li, et al. (2013) Sodium hyaluronate decreases ocular surface toxicity induced by benzalkonium chloride-preserved latanoprost: an in vivo study. Invest Ophthalmol Vis Sci 54(5): 3385-3393.

34. Takashi Kojima, Taeko Nagata, Haruka Kudo, Wolfgang G. K. MüllerLierheim, et al. (2020) The Effects of High Molecular Weight Hyaluronic Acid Eye Drop Application in Environmental Dry Eye Stress Mice. Int J Mol Sci 21.

35. Gysbert-Botho van Setten, Christophe Baudouin, Jutta Horwath-Winter, Daniel Böhringer, Oliver Stachs, et al. (2020) The HYLAN M Study: Efficacy of $0.15 \%$ High Molecular Weight Hyaluronan Fluid in the Treatment of Severe Dry Eye Disease in a Multicenter Randomized Trial. J Clin Med 9(11).

36. Gysbert-Botho van Setten, Oliver Stachs, Bénédicte Dupas,Semra Akkaya Turhan, Berthold Seitz, et al. (2020) High Molecular Weight Hyaluronan Promotes Corneal Nerve Growth in Severe Dry Eyes. J Clin Med 9(12).

37. Ripal Gaudana, Hari Krishna Ananthula, Ashwin Parenky, Ashim K Mitra (2010) Ocular drug delivery. AAPS J 12(3): 348-360.

38. PubChem Compound Summary for CID 5311221, Latanoprost. National Center for Biotechnology Information.

39. John Liu, Ticiana De Francesco, Matthew Schlenker, Iqbal Ike Ahmed (2020) Icare Home Tonometer: A Review of Characteristics and Clinical Utility. Clin Ophthalmol 14: 4031-4045

40. Yaniv Barkana, Sarah Anis, Jeffrey Liebmann, Celso Tello, Robert Ritch (2006) Clinical utility of intraocular pressure monitoring outside of normal office hours in patients with glaucoma. Arch Ophthalmol 124(6): 793-797.

41. Kaweh Mansouri, Angelo P Tanna, Carlos Gustavo De Moraes, Andrew S Camp, Robert N Weinreb (2020) Review of the measurement and management of 24-hour intraocular pressure in patients with glaucoma. Surv Ophthalmol 65(2): 171-186.

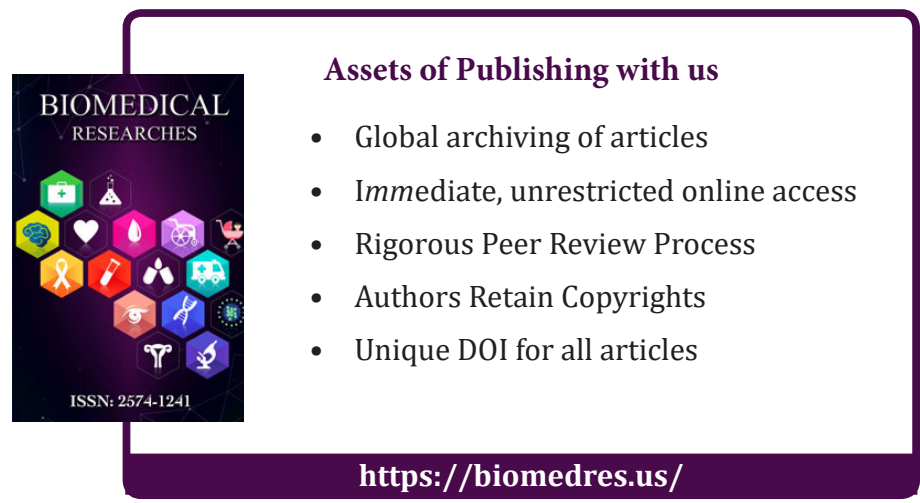

Copyright@ Wolfgang GK Müller-Lierheim | Biomed J Sci \& Tech Res | BJSTR. MS.ID.005958. 